\title{
Prototipe Akses Pintu Masuk Stadion Terintegrasi dengan Kartu RFID sebagai Tiket Berbasis Arduino Uno
}

\author{
HIDAYAT NUR ISNIANTO, ADAM AGUSTIAN \\ Departemen Teknik Elektro dan Informatika, Sekolah Vokasi, Universitas Gadjah Mada \\ Email: hnisnianto@ugm.ac.id
}

Received 14 April 2019 | Revised 15 Juni 2019 | Accepted 10 Juli 2019

\begin{abstract}
ABSTRAK
Sepak bola merupakan olah raga yang digemari masyarakat sebagai hiburan. Di stadion sering dijumpai penonton tanpa tiket atau dengan tiket palsu, sehingga menyebabkan kerugian penyelenggara. Pada makalah ini dibuat prototipe akses masuk stadion dengan mengimplementasikan Radio Frequency Identification (RFID) untuk tiket dan kunci akses pintu masuk stadion, dengan tujuan mencegah penonton masuk ke stadion dengan tiket palsu atau tanpa tiket, dan tiket dapat dimanfaatkan kembali. Sistem ini menggunakan RFID tag berbentuk kartu sebagai tiket dan dibaca dengan RFID Reader RDM 6300 untuk dibandingkan dengan data yang disimpan pada SD Card, jika sesuai maka solenoid aktif dan penonton dapat masuk stadion, sedangkan jika tidak sesuai, maka pintu stadion tidak dapat dibuka. Dari hasil pengujian, sistem mekanik dapat berfungsi sesuai dengan yang diharapkan dan seluruh RFID tag dapat dikenali dalam jarak optimal $3 \mathrm{~cm}$. Keseluruhan pengguna yang telah terdaftar dapat membuka pintu.
\end{abstract}

Kata kunci: Tiket, Stadion, Arduino, RFID, RDM6300

\begin{abstract}
Football is a sport that is loved by society as an entertainment. In stadiums, there are often spectators without tickets or with fake tickets, causing losses to the organizers. In this paper a prototype of stadium entrance access was made by implementing Radio Frequency Identification (RFID) for tickets and access keys to stadium entrances, with the aim of preventing viewers from entering the stadium with fake tickets or no tickets, and tickets can be reused. This system uses cardshaped RFID tags as tickets and is read with an RDM 6300 RFID Reader to be compared with data stored on the SD Card, if it matches then the solenoid is active and the viewer can enter the stadium, whereas if it is not appropriate, the stadium door cannot be opened. From the results of testing, the mechanical system can function as expected and the entire RFID tag can be identified at an optimal distance of $3 \mathrm{~cm}$. All registered users can open the door.
\end{abstract}

Keywords: Ticket, Stadium, Arduino, RFID, RDM6300 
Hidayat Nur Isnianto, Adam Agustian

\section{PENDAHULUAN}

Sepak bola merupakan olah raga yang digemari masyarakat sebagai sebuah hiburan mulai dari anak-anak hingga orang dewasa atau sering disebut sebagai olah raga hiburan (sportainment). Emosional yang ditimbulkan ketika menonton pertandingan sepak bola memiliki rasa tersendiri bagi penontonnya, terutama ketika menonton secara langsung di dalam stadion sebagai suporter yang berhasrat mendukung timnya untuk memenangkan pertandingan. Akan tetapi, hubungan antara sepak bola, tim, dan suporter sering kali dinodai oleh tindakan tidak sepantasnya oleh oknum calo tiket dengan adanya kasus tiket palsu, sehingga sejumlah suporter tertahan di gerbang pemindaian tiket karena terbukti datang dengan tiket palsu dan tidak dapat masuk ke dalam stadion untuk mendukung aksi tim jagoannya berlaga (Silaban, 2019). Tiket palsu yang beredar memang sangat mirip dengan aslinya. Bahkan, cukup sulit membedakannya andai belum dilakukan scan oleh panitia pelaksana pertandingan (Anonim, 2019). Hal ini selain merugikan penonton juga sangat merugikan klub yang menyelenggarakan pertandingan, karena klub-klub di Indonesia masih sangat mengandalkan pemasukan finansial dari hasil penjualan tiket pertandingan.

Saat ini akses pintu masuk stadion oleh pemegang tiket belum terintegrasi secara otomatis, sehingga penonton dengan tiket palsu ataupun tanpa tiket kadang kala dapat memasuki stadion secara leluasa dengan memanfaaatkan petugas penjaga pintu lengah atau kurang teliti, oleh karena itu pada penelitian ini mengambil topik prototipe akses pintu masuk stadion yang terintegrasi dengan kartu RFID sebagai tiket berbasis Arduino Uno, dimana dengan penggunaan tiket RFID yang terintegrasi dengan pintu akses stadion diharapkan dapat meningkatkan pelayanan dan kenyamanan terhadap penonton yang membeli tiket dari loket resmi ketika melihat pertandingan sepak bola di dalam stadion serta mencegah kebocoran tiket yang dilakukan oleh oknum-oknum yang tidak bertanggung jawab.

Tiket konvensional selama ini diperiksa secara manual oleh petugas, sehingga pada makalah ini dibuat suatu sistem identifikasi untuk tiket secara otomatis yang terintegrasi dengan akses pintu stadion. Sistem untuk mengidentifikasi suatu objek secara otomatis (Auto ID) ada berbagai macam, diantaranya Barcode Optical Character Recognition (OCR), biometric, smartcard, dan RFID (Radio Frequency Identification). RFID dikategorikan komunikasi private dengan teknologi identifikasi berbasis gelombang radio. Metode identifikasinya menggunakan sarana yang disebut RFID transponder (tag) untuk menyimpan dan mengambil data. Teknologi ini mampu mengidentifikasi berbagai objek secara simultan tanpa memerlukan kontak langsung dengan objek dalam jarak pendek (Finkenzeller, 2010).

Teknologi RFID merupakan bagian dari RF (Radio Frequency) yang digunakan sebagai media identifikasi secara wireless yang terdiri dari dua komponen yaitu (a) RFID transponder (tag) yang memiliki identifikasi unik dan memori yang dapat ditulis, dan (b) RFID reader untuk mengidentifikasi RFID tag. Pembaca RFID (RFID reader) merupakan penghubung antara perangkat lunak aplikasi dengan RFID reader melalui antena untuk memancarkan gelombang radio ke RFID transponder (tag) (Karygiannis, Eydt, Barber, Bunn, \& Phillips, 2007).

RFID juga telah diimplementasikan sebagai pengganti model sistem absensi tanda tangan harian yang memiliki kelemahan dan umum terjadi hampir di seluruh instansi, yaitu: pemalsuan tandatangan; tanda tangan di luar tenggat waktu yang telah ditetapkan; rekapitulasi yang memakan waktu; boros kertas dan tinta; dan kurangnya validitas data absensi (Cahyadi, 2009). Sedangkan (Kamarulazizi \& Ismail, 2010) mengaplikasikan RFID untuk otomatisasi proses tol dengan cara memasang RFID tag pada kaca depan kendaraan, sehingga menghilangkan kebutuhan pengendara kendaraan bermotor dan otoritas tol untuk melakukan pembayaran tiket dan pengumpulan biaya tol secara manual. Informasi 
data juga mudah didapatkan antara pengendara dan otoritas tol, sehingga sistem tol lebih efisien dengan mengurangi lalu lintas dan menghilangkan kemungkinan kesalahan manusia.

Pada Sistem Supply Chain (Owunwanne \& Goel, 2016), RFID digunakan untuk melacak pergerakan barang. Identitas sebuah benda dengan nomor seri unik yang ditransmisikan secara nirkabel ke sistem komputer dengan menggunakan framework komputasi awan (cloud) sehingga dapat mengurangi biaya.

Sirkulasi dan pengaturan bahan bacaan di rak perpustakaan merupakan pekerjaan yang tidak praktis yang menghabiskan sebagian besar waktu staf perpustakaan, maka dengan RFID dapat mengurangi jumlah waktu yang dibutuhkan untuk melakukan operasi sirkulasi (Singh \& Mahajan, 2014). Sedangkan (Santoso \& Lesmana, 2014) telah mengimplementasikan RFID untuk sistem manajemen aset berkaitan dengan pengelolaan dan pemeriksaan aset sehingga pemeriksaan menjadi otomatif, efektif, dan efisien. Selain itu RFID juga dapat digunakan untuk sistem akses ruangan. Hasil yang diperoleh adalah semua tag dapat dikenali oleh RFID reader dalam tiga posisi berbeda dengan jarak optimal sejauh $5 \mathrm{~cm}$ pada posisi vertikal dan $2 \mathrm{~cm}$ pada posisi horizontal (Rachmat \& Hutabarat, 2014).

\section{METODE PENELITIAN}

Rancangan prototipe akses pintu masuk stadion yang terintegrasi dengan kartu RFID sebagai tiket berbasis Arduino Uno dibagi menjadi tiga bagian yaitu bagian sistem elektronik, sistem mekanik, dan perangkat lunak. Sistem elektronik ini berfungsi untuk membaca, memvalidasi tiket penonton, dan membuka pintu masuk stadion. Hanya penonton dengan karcis ber-RFID yang sudah terdaftar yang dapat memasuki stadion. Untuk blok diagram bagian sistem elektronik seperti terlihat pada Gambar 1.a.

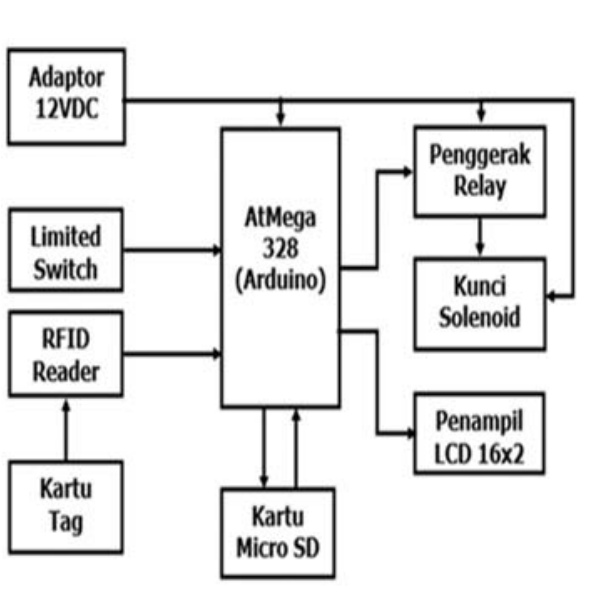

(a)

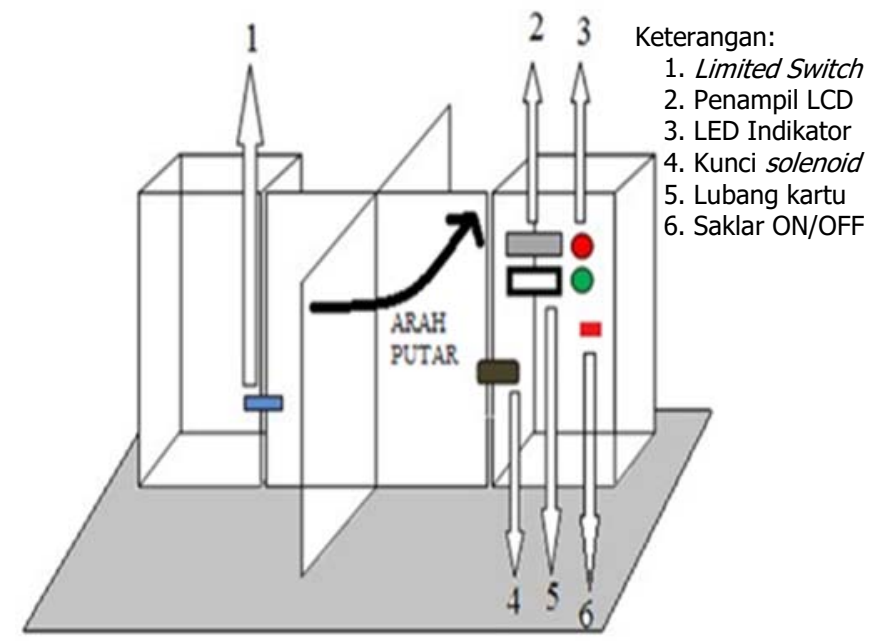

(b)

Gambar 1. (a) Blok Diagram Sistem Elektronik, (b) Rancangan Sistem Mekanik

Pada Gambar 1.a tersebut terdiri dari RFID tag dan RFID reader (yang disebut sebagai modul RFID), Arduino, limited switch, penggerak relay, solenoid door lock, modul kartu mikro SD, penampil LCD 16x2, dan catu daya. Rancangan prototipe untuk sistem mekanik yang dibuat seperti pada Gambar 1.b. 
Cara kerja sistem dari Gambar 1.b dimulai dengan pengaturan saklar suplai ke posisi ON (6) agar sistem elektronis aktif, kemudian kartu RFID tag yang difungsikan sebagai tiket untuk identifikasi personal dimasukkan pada bagian mekanik yang sudah ditentukan (5), kartu tersebut akan dideteksi oleh RFID reader. Data unik pada RFID tag ini akan diidentifikasi oleh RFID readeryang kemudian data tersebut akan dibandingkan dengan data yang tersimpan pada memori Arduino. Hasil proses perbandingan data ini akan ditunjukkan pada penampil LCD 16x2 (2) dan LED indikator (3). Sistem akan membuka kunci solenoid untuk pintu elektrik (4), jika data RFID tag sesuai dan penonton dapat masuk melalui pintu putar. Setelah pintu berputar $1 / 4$ putaran dan limit switch (1) aktif, dan pintu akan terkunci kembali. Penonton berikutnya harus memasukkan RFID tag pada tempatnya, agar pintu dapat dibuka kembali. Sedangkan diagram alir untuk sistem perangkat lunak seperti pada Gambar 2.

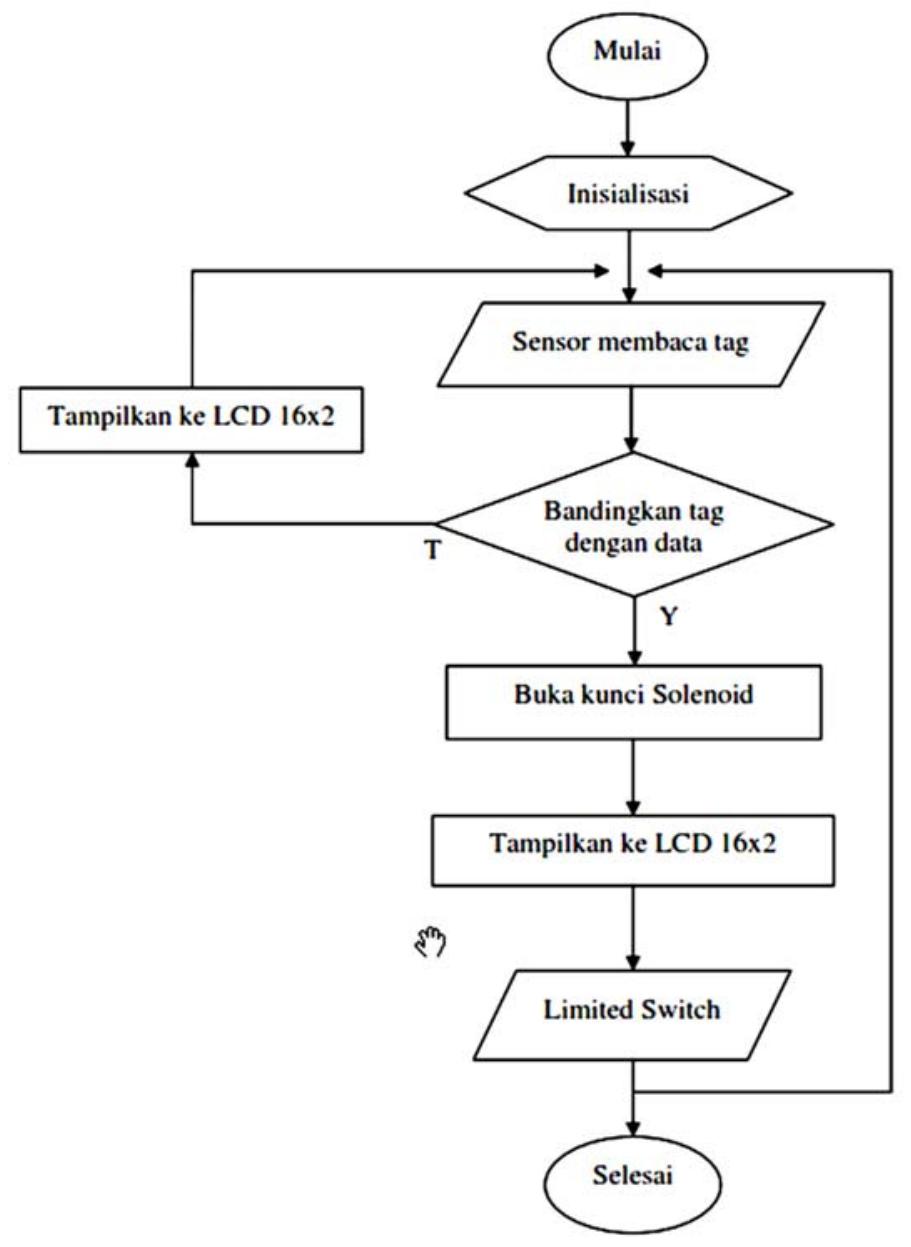

Gambar 2. Diagram Alir Sistem

\subsection{RFID Reader}

RFID reader atau pembaca RFID tag menggunakan tipe RDM 6300 dengan frekuensi $125 \mathrm{KHz}$. Suplai tegangan pembaca tag pada P3 terhubung ke pin Arduino 5V $V_{D C}$ dan GND. Pin 1 dan 2 pada P2 merupakan pin untuk antena yang digunakan untuk menerima gelombang radio yang dipancarkan oleh RFID tag. Rangkaian RFID reader dengan Arduino seperti pada Gambar 3. 


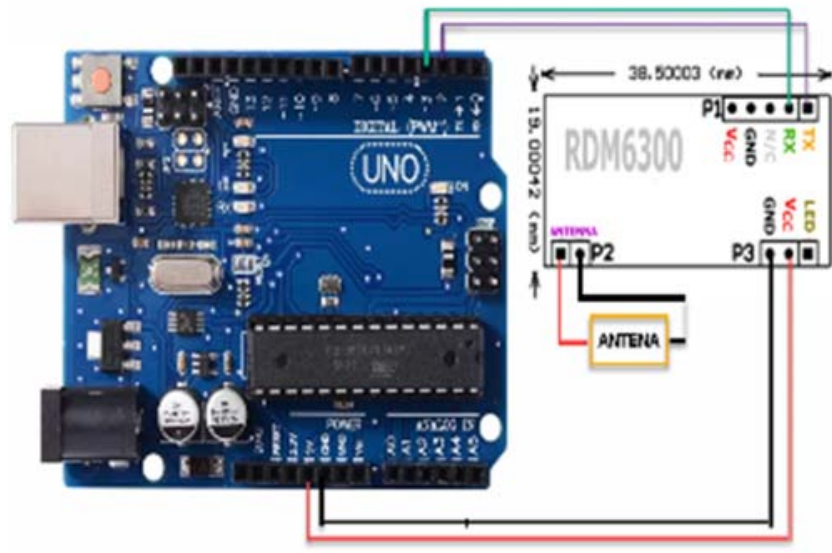

\section{Gambar 3. Rangkaian Pengkabelan Arduino dengan RFID Reader}

Pin keluaran TX pada P1 dari pembaca tag dihubungkan dengan pin D2 Arduino dan pin keluaran RX pada P1 dari pembaca tag dihubungkan dengan pin D3 Arduino, pin RX dan TX ini merupakan pin komunikasi serial agar nantinya perangkat bisa saling terhubung karena pembaca tag menggunakan sistem komunikasi serial untuk keluarannya.

\subsection{RFID Tag}

RFID tag yang digunakan memiliki frekuensi $125 \mathrm{KHz}$, hal ini menyesuaikan kemampuan dari RFID reader yang digunakan yaitu tipe RDM 6300 memiliki frekuensi $125 \mathrm{KHz}$. Bentuk dan struktur dari bagian dalam atau komponen yang ada di dalam kartu tag dapat dilihat pada Gambar 4, bagian kumparan merupakan antena pemancar dari kartu tag, sedangan IC merupakan prosesor dari tag tersebut yang nantinya akan mengirim sinyal yang berisi kode tag melalui antena tersebut.

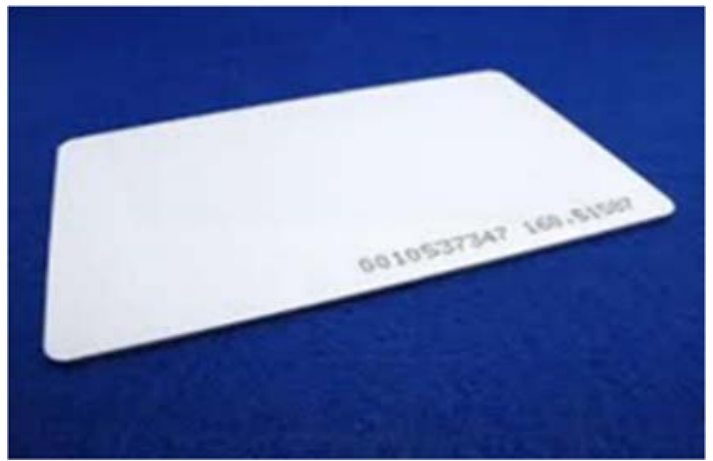

(a)

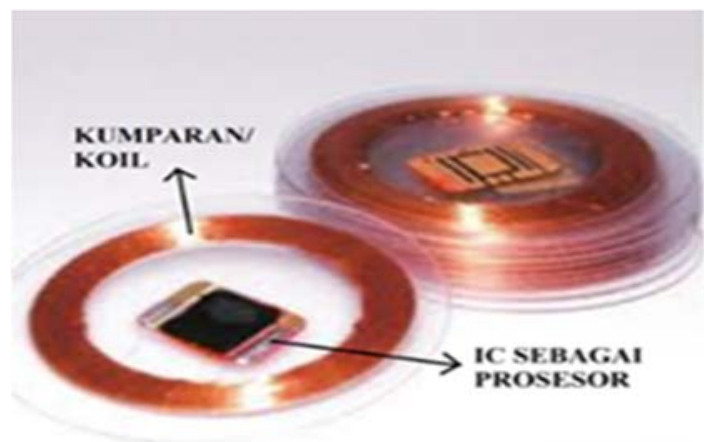

(b)

Gambar 4. (a) Kartu RFID Tag, (b) Kompenen dalam RFID Tag

\subsection{Penggerak Relay dan Kunci Solenoid}

Penggerak relay digunakan karena terdapat perbedaan tegangan antara Arduino dengan kunci solenoid. Keluaran dari pin Arduino akan dihubungkan dengan relay sehingga relay yang akan menjadi penggerak kunci solenoid dengan instruksi dari Arduino. Rangkaian penggerak relay untuk kunci solenoid seperti terlihat pada Gambar 5. 


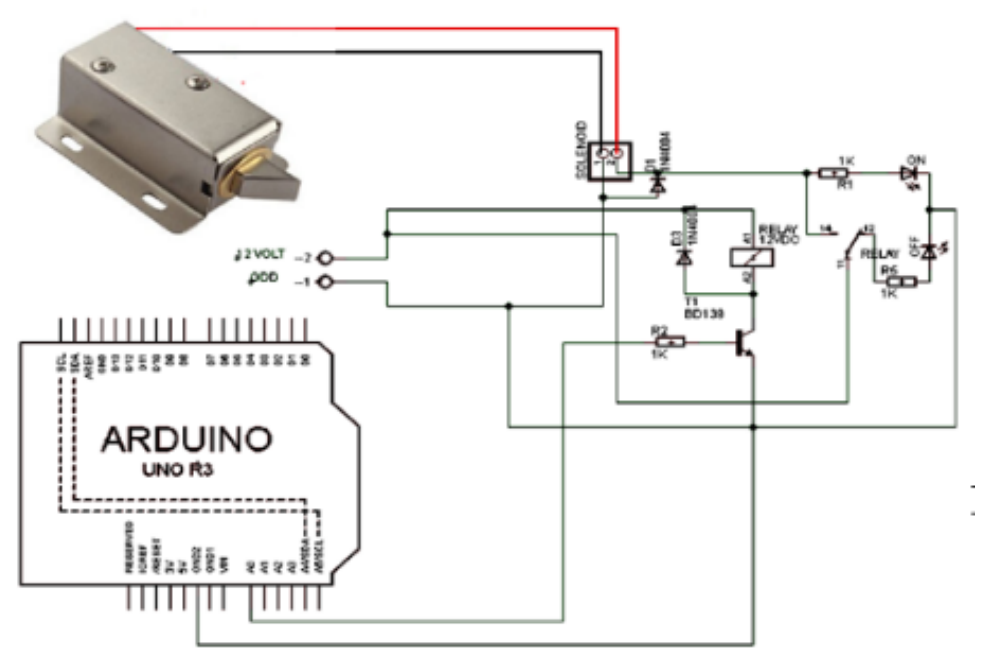

Gambar 5. Penggerak Relay

Dari Gambar 5, suplai penggerak relay adalah $12 \mathrm{~V}_{\mathrm{DC}}$ dan menerima input dari Arduino agar dapat dikendalikan dalam kondisi tertentu. Penggerak relay juga memiliki output NO, NC dan $12 V_{D C}$. Masukan dari COM Arduino merupakan logika untuk menggerakan relay. Sebelum masuk ke relay ditambahkan transistor BD139 yang berfungsi sebagai saklar, karena adanya perbedaan tegangan antara Arduino $5 \mathrm{~V}_{\mathrm{DC}}$ dengan tegangan relay sebesar $12 \mathrm{~V}_{\mathrm{DC}}$.

\subsection{Limited Switch}

Limited switch digunakan sebagai masukan untuk Arduino dan mendapat logika high dari Arduino melalui pin $\mathrm{A} 1$ dengan tegangan $5 \mathrm{~V}_{D C}$ yang dihubungkan dengan pin COM pada limited switch sedangan pin NO atau Normaly Open pada limited switch dihubungkan dengan pin GND pada Arduino. Rangkaian limited switch seperti pada Gambar 6.

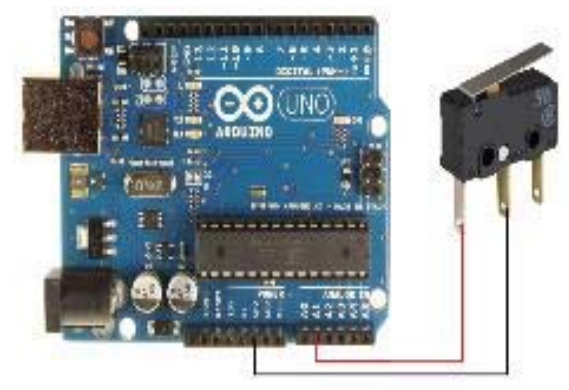

Gambar 6. Rangkaian Arduino dengan Limited Switch

Cara kerjanya yaitu ketika pintu diputar akan menyentuh limited switch yang semula dalam kondisi open berubah menjadi close. Hal ini membuat Arduino memberi logika low pada relay yang terhubung ke solenoid sehingga kunci solenoid akan mengunci kembali.

\subsection{Kartu Memori Mikro SD}

Kartu memori digunakan sebagai media penyimpanan data kode tag yang diregistrasikan, nantinya data yang tersimpan ini menjadi data pembanding dengan tag yang terbaca. Pada kartu memori data akan disimpan dengan format file .txt, nama file tersebut merupakan kode tag yang diregistrasikan. Pada proses meregistrasikan kartu digunakan program untuk menulis kode kartu pada memori. Ketika kartu tag terbaca oleh pembaca maka secara otomatis 
program akan menuliskan kode kartu tersebut pada kartu memori. Rangkaian Arduino dengan modul memori mikro SD seperti pada Gambar 7.

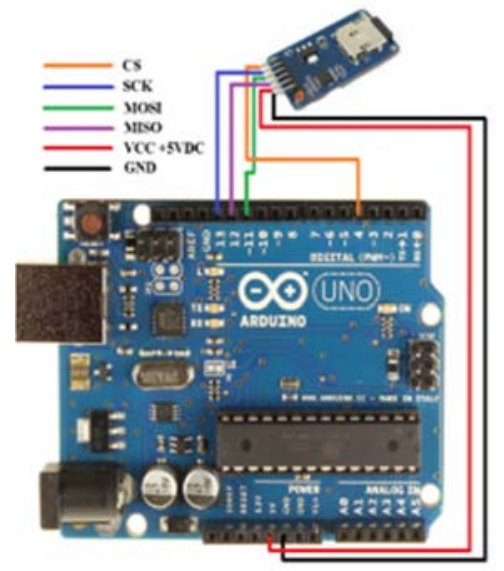

\section{Gambar 7. Pengkabelan Arduino dengan Modul Mikro SD}

Untuk penulisan kode tag yang akan diregistrasi pada kartu memori, maka digunakan modul mikro SD untuk mempermudah proses perancangan perangkat, tag yang terbaca oleh reader akan disimpan dalam kartu memori dan jika kode tag telah tersimpan, maka akan dilakukan pembacaan melalui PC untuk mengetahui tag telah tersimpan atau tidak, jika tag telah tersimpan maka akan ditampilkan "nama file.txt exist", sedangkan jika kode tag gagal disimpan maka yang akan ditampilkan dalam PC "nama file.txt doesn't exist".

\subsection{Prototipe Sistem Keseluruhan}

Hasil implementasi gabungan bagian sistem elektronik, sistem mekanik, dan perangkat lunak dari perancangan prototipe akses pintu masuk stadion yang terintegrasi dengan kartu RFID sebagai tiket berbasis Arduino Uno seperti terlihat pada Gambar 8.

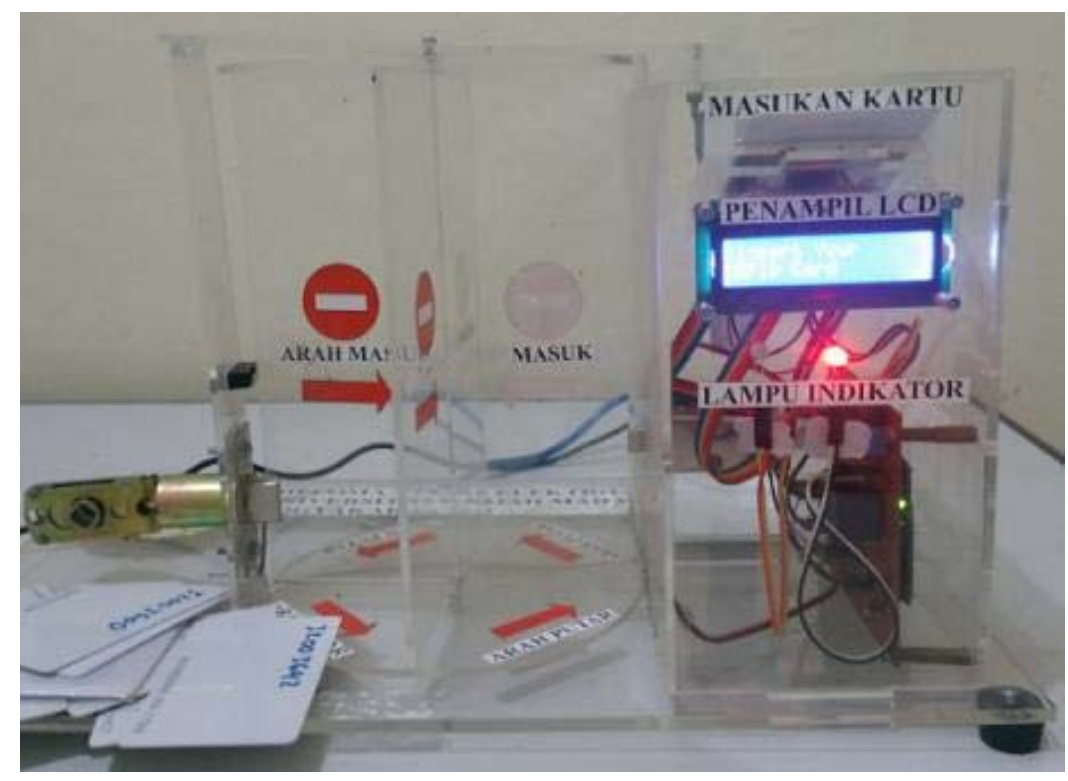

Gambar 8. Prototipe Akses Pintu Stadion yang Terintegrasi dengan Kartu RFID 


\section{HASIL DAN PEMBAHASAN}

\subsection{Kemampuan Jarak Pembacaan Reader dengan Tag}

Pada bagian ini dilakukan pengujian jarak pembacaan dari RFID tag dengan RFID reader dalam posisi horisontal, karena desain mekanik yang digunakan sudah tersedia tempat untuk memposisikan RFID tag pada prototipe sistem mekanik pintu stadion. Pada sistem mekanik yang dibuat, kartu RFID dirancang menempel pada antena RFID reader yang dibatasi dengan papan akrilik setebal $5 \mathrm{~mm}$. Hasil pengujian seperti pada Tabel 1.

Tabel 1. Kemampuan Jarak Pembacaan Reader dengan Tag

\begin{tabular}{|c|c|c|c|c|c|c|}
\hline \multirow{2}{*}{$\begin{array}{c}\text { RFID } \\
\text { Taq }\end{array}$} & \multicolumn{6}{|c|}{ Jarak RFID Tag (cm) dengan RFID Reader (RDM 6300) } \\
\hline & 1 & 2 & 3 & 5 & 7 & 10 \\
\hline Kartu 1 & Terbaca & Terbaca & Terbaca & Terbaca & Tidak & Tidak \\
\hline Kartu 2 & Terbaca & Terbaca & Terbaca & Tidak & Tidak & Tidak \\
\hline Kartu 3 & Terbaca & Terbaca & Terbaca & Terbaca & Tidak & Tidak \\
\hline Kartu 4 & Terbaca & Terbaca & Terbaca & Terbaca & Tidak & Tidak \\
\hline Kartu 5 & Terbaca & Terbaca & Terbaca & Tidak & Tidak & Tidak \\
\hline Kartu 6 & Terbaca & Terbaca & Terbaca & Terbaca & Tidak & Tidak \\
\hline Kartu 7 & Terbaca & Terbaca & Terbaca & Tidak & Tidak & Tidak \\
\hline Kartu 8 & Terbaca & Terbaca & Terbaca & Tidak & Tidak & Tidak \\
\hline Kartu 9 & Terbaca & Terbaca & Terbaca & Terbaca & Tidak & Tidak \\
\hline Kartu 10 & Terbaca & Terbaca & Terbaca & Terbaca & Tidak & Tidak \\
\hline Kartu 11 & Terbaca & Terbaca & Terbaca & Tidak & Tidak & Tidak \\
\hline Kartu 12 & Terbaca & Terbaca & Terbaca & Terbaca & Tidak & Tidak \\
\hline Kartu 13 & Terbaca & Terbaca & Terbaca & Terbaca & Tidak & Tidak \\
\hline Kartu 14 & Terbaca & Terbaca & Terbaca & Tidak & Tidak & Tidak \\
\hline Kartu 15 & Terbaca & Terbaca & Terbaca & Terbaca & Tidak & Tidak \\
\hline
\end{tabular}

Dari Tabel 1 terlihat bahwa pembacaan RFID tag oleh RFID reader pada posisi horisontal terbaca dengan baik pada jarak $3 \mathrm{~cm}$, pada jarak $5 \mathrm{~cm}$ tidak semua dapat terbaca, dan mulai jarak $7 \mathrm{~cm}$ sudah tidak terbaca. Jarak terbaiknya untuk pembacaan maksimal $3 \mathrm{~cm}$.

\subsection{Pengujian Driver Relay}

Pada pengujian ini rangkaian driver relay dikendalikan dari pin $\mathrm{A}_{0}$ Arduino. Ketika pin $\mathrm{A}_{0}$ diberi logika 1 (high), maka relay akan aktif dan aliran listrik akan putus pada bagian Normally Open (NO), sebaliknya jika diberikan logika 0 (low) maka relay tidak akan aktif. Hasil pengujian seperti pada Gambar 9.a untuk relay aktif dan 9.b ketika relay tidak aktif.

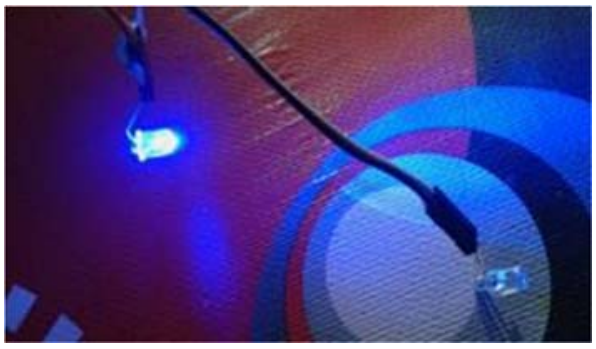

(a)

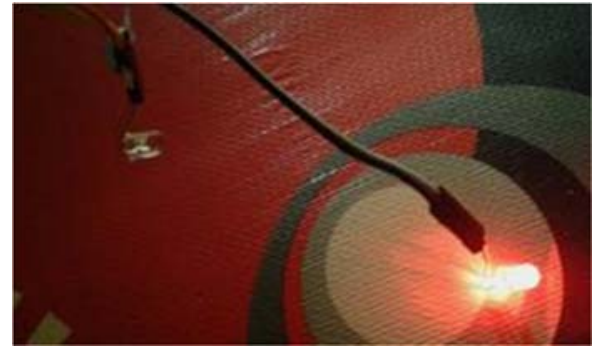

(b)

Gambar 9. (a) Indikator LED ketika Relay Aktif, (b) Indikator LED ketika Relaytidak Aktif 
Dari Gambar 9, tegangan keluaran $12 V_{D C}$ akan berpindah yang semula keluarannya berada di pin NO akan berpindah ke pin NC yang terhubung dengan LED berwarna biru. Ketika relay pada kondisi tidak aktif maka LED berwarna merah yang terhubung dengan relay pada pin NO akan menyala, sedangkan ketika relay aktif maka LED warna biru yang terhubung dengan relay pin NC akan menyala.

\subsection{Pengujian Sistem Keseluruhan}

Setelah dilakukan pengujian pada setiap bagian-bagian dari alat ini, maka selanjutnya dilakukan pengujian sistem secara keseluruhan. Sesuai dengan perencanaan awal, pengujian dilakukan mulai dari membuat data kartu yang akan diberi akses untuk masuk, yaitu dengan program penulisan pada kartu memori. Ketika kartu tag dimasukan dan terbaca oleh RFID reader lalu ditulis atau disimpan ke dalam memori dengan format .txt, jika kode kartu telah tertulis pada memori maka penampil LCD akan menampilkan nomor UID dan juga tulisan "Terdaftar" seperti pada Gambar 10.

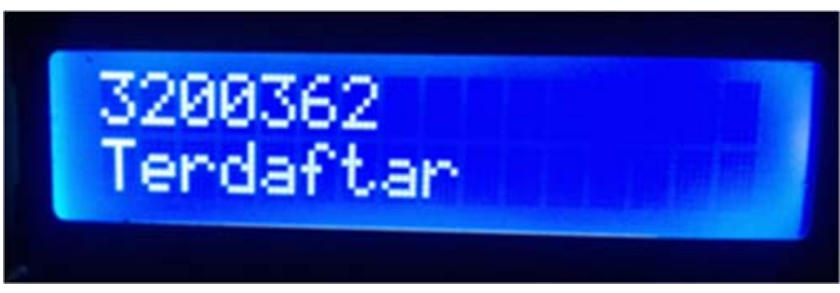

\section{Gambar 10. Tampilan LCD ketika Kode Tag telah Tertulis}

Untuk memastikan bahwa kode telah tertulis atau tidak, maka dapat dilakukan melalui komputer. Jika kode tag sudah tertulis maka program yang telah dibuat untuk penulisan data pada kartu memori telah benar. Hasilnya seperti yang terlihat pada Gambar 11.

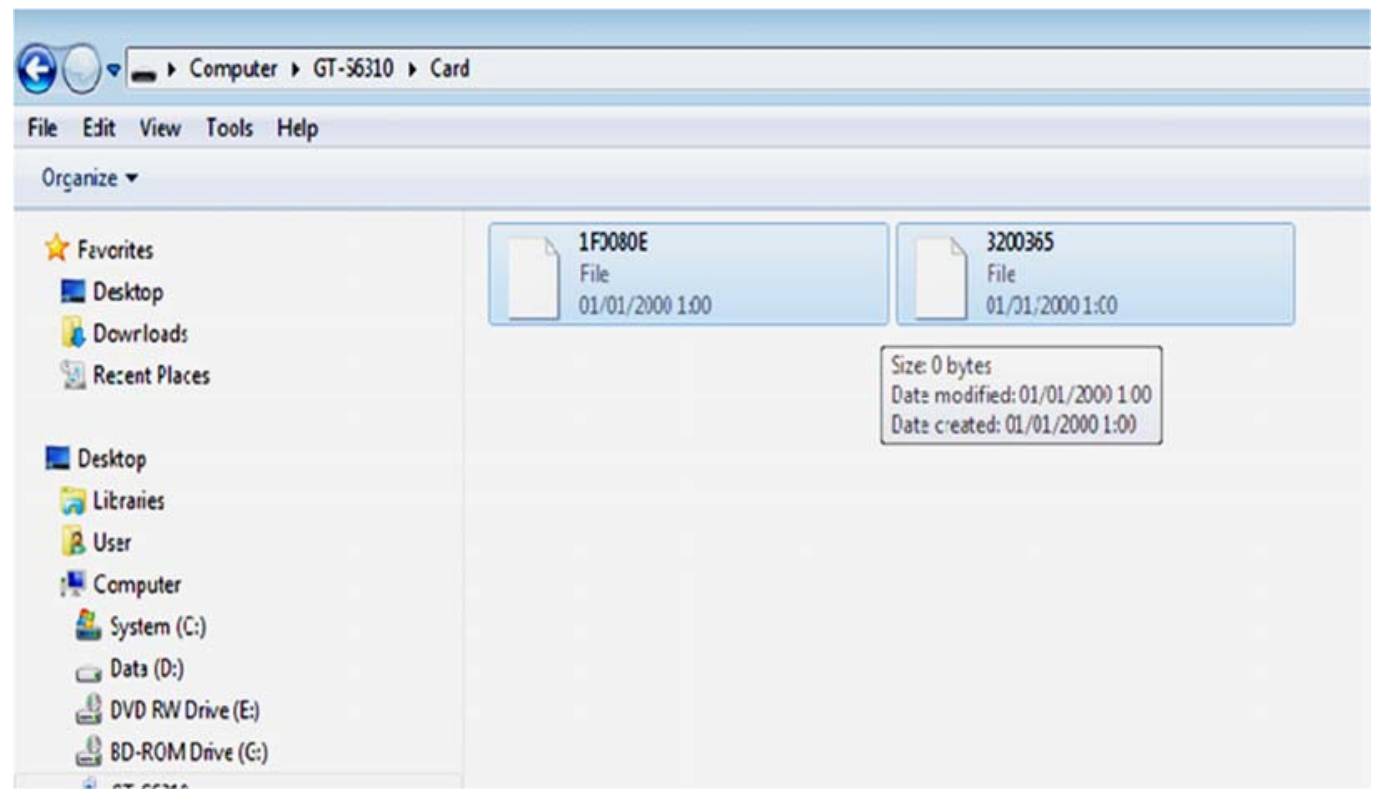

Gambar 11 File .txt dengan Nama File Kode Tag

Setelah pembuatan data tag pada kartu memori selanjutnya Arduino diberi program yang berbeda, yaitu program untuk akses masuk dimana program tersebut akan mem-verifikasi dan membandingkan kode yang terbaca dengan data kode yang ada di dalam kartu memori, jika 
kode kartu yang terbaca tersebut ada yang sama dengan kode kartu yang ada di dalam kartu memori, maka program akan membuka kunci solenoid melalui relay yang digerakkan oleh transistor BD139 sebagai saklar yang mendapat logika dari output Arduino.

Dalam kondisi standby LCD menampilkan tulisan seperti pada Gambar 12 dimana kondisi ini sebagai kondisi awal, RFID reader belum menerima atau membaca kartu.

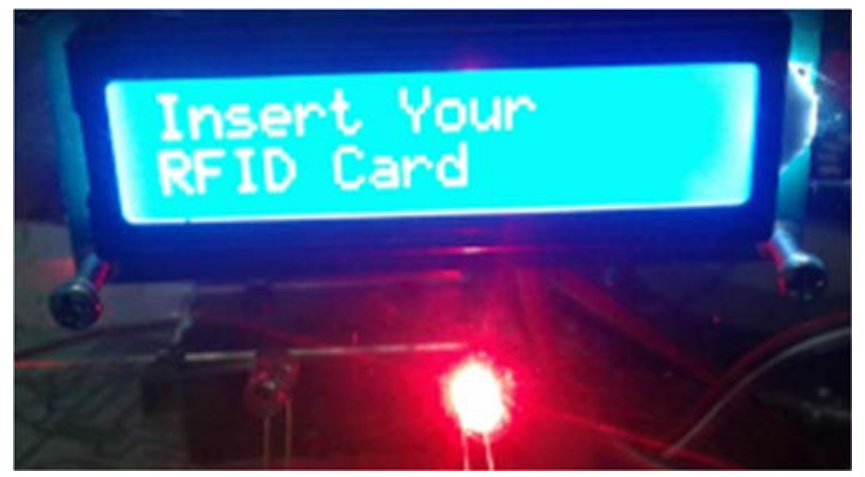

Gambar 12. Tampilan dalam Kondisi Standby

Setelah ada kartu yang dimasukan atau terbaca, maka penampil pada LCD dan juga LED sebagai indikator akan ada perubahan. Hal ini seperti pada Gambar 13.

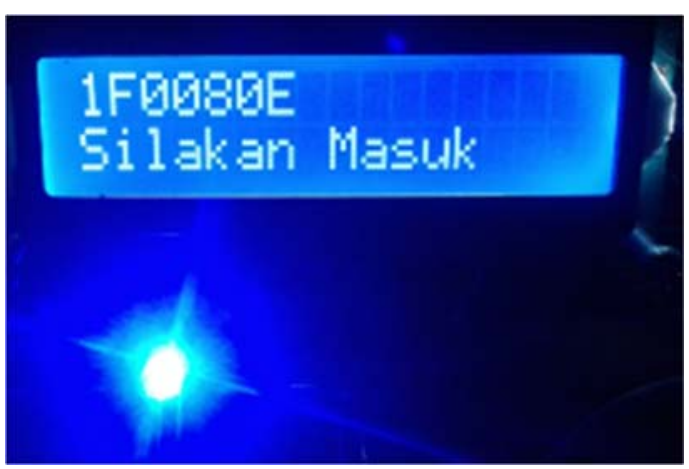

(a)

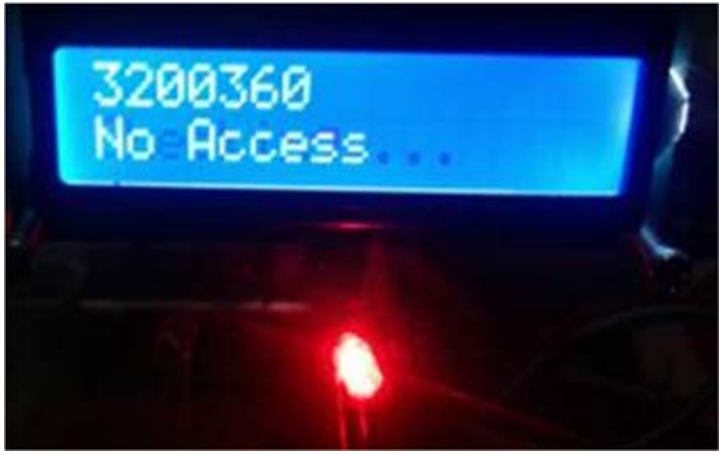

(b)

Gambar 13. Tampilan LCD, (a) Kartu Tag Terverifikasi, (b) Kartu Tag tidak Terverifikasi

Setelah kartu tag terbaca kemudian dibandingkan dengan kode tag yang terdapat di dalam kartu memori SD Card dan penampil serta lampu indikator akan aktif. Ketika kode tag terverifikasi kunci solenoid akan terbuka, LED warna biru menyala, dan penampil menuliskan "Silahkan Masuk" seperti Gambar 13.a.

Jika kode yang terbaca tidak ada di dalam kartu memori, maka kunci solenoid tidak terbuka, indikator LED merah akan menyala dan penampil menampilkan tulisan "No Access" seperti pada Gambar 13.b. Kemudian sistem akan kembali ke kondisi awal dimana penampil memberi indikator untuk memasukan kartu tag kembali.

Jika pintu telah terbuka, limited switch selanjutnya akan bekerja untuk mengembalikan posisi kunci solenoid kepada posisi semula yaitu mengunci pintu agar pintu tidak dapat membuka. Limited switch memberi masukan kepada Arduino agar ketika limited switch aktif program 
Arduino kembali ke keadaan semula, yaitu ketika Arduino meminta kartu untuk dimasukan kembali ke dalam lubang pada prototipe mekanik sistem.

Pengujian sistem keseluruhan dilakukan dengan 15 kartu yang sudah diuji pembacaannya pada jarak maksimal $3 \mathrm{~cm}$. Dari 15 kartu tersebut, 10 kartu sudah diprogram dan 5 kartu tidak diprogram. Hasil pengujian untuk berbagai kartu seperti pada Tabel 2.

Tabel 2. Pengujian Akses Pintu dengan RFID Tag

\begin{tabular}{|c|c|c|c|c|}
\hline $\begin{array}{c}\text { Kartu } \\
\text { Tag }\end{array}$ & Penampil LCD & $\begin{array}{c}\text { LED } \\
\text { Indikator }\end{array}$ & $\begin{array}{c}\text { Solenoid Door } \\
\text { Lock }\end{array}$ & Keterangan \\
\hline Kartu 1 & Silahkan Masuk & Hijau & terbuka & terprogram \\
\hline Kartu 2 & Silahkan Masuk & Hijau & terbuka & terprogram \\
\hline Kartu 3 & No Access & Merah & terkunci & belum terprogram \\
\hline Kartu 4 & No Access & Merah & terkunci & belum terprogram \\
\hline Kartu 5 & Silahkan Masuk & Hijau & terbuka & terprogram \\
\hline Kartu 6 & Silahkan Masuk & Hijau & terbuka & terprogram \\
\hline Kartu 7 & Silahkan Masuk & Hijau & terbuka & terprogram \\
\hline Kartu 8 & Silahkan Masuk & Hijau & terbuka & terprogram \\
\hline Kartu 9 & No Access & Merah & terkunci & belum terprogram \\
\hline Kartu 10 & Silahkan Masuk & Hijau & terbuka & terprogram \\
\hline Kartu 11 & Silahkan Masuk & Hijau & terbuka & terprogram \\
\hline Kartu 12 & No Access & Merah & terkunci & belum terprogram \\
\hline Kartu 13 & No Access & Merah & terkunci & belum terprogram \\
\hline Kartu 14 & Silahkan Masuk & Hijau & terbuka & terprogram \\
\hline Kartu 15 & Silahkan Masuk & Hijau & terbuka & terprogram \\
\hline
\end{tabular}

Dari Tabel 2 terlihat bahwa semua RFID tag yang sudah diprogram dapat digunakan untuk mengaktifkan solenoid door lock, sehingga prototipe pintu stadion dapat dibuka 1/4 putaran, setelah itu akan terkunci kembali. Sedangkan 5 RFID tag yang belum diprogram tidak dapat digunakan untuk mengaktifkan solenoid door lock, sehingga prototipe pintu stadion tetap terkunci dan tidak dapat diputar.

\section{KESIMPULAN}

Dari hasil pengujian diperoleh kesimpulan untuk penelitian sistem ini adalah sebagai berikut:

1. Sistem yang dibuat dapat bekerja dengan baik, mulai dari prototipe sistem mekanik, catu daya, pembaca RFID tag, basis data pada mikro SD, driver relay, hingga LCD.

2. Sensor pembaca RFID tag bekerja dengan baik pada jarak pembacaan maksimal adalah 3 $\mathrm{cm}$ dengan posisi horisontal dan dapat melakukan validasi 15 buah RFID tag dengan baik.

3. RFID tag sejumlah 10 buah yang sudah diprogram semua dapat digunakan untuk mengakses pintu dan muncul tulisan "Silakan Masuk", sedangkan 5 buah yang yang belum diprogram tidak dapat digunakan untuk mengakses. 


\section{DAFTAR RUJUKAN}

Anonim. (2019). Tiga Langkah Persija Antisipasi Tiket Palsu. Diambil kembali dari https://www.bola.net/indonesia/tiga-langkah-persija-antisipasi-tiket-palsua7112e.html: https://www.bola.net/

Cahyadi, D. (2009). Desain Sistem Absensi PNS Berbasis Teknologi RFID. Jurnal Informatika Mulawarman, 4(3), 29-36.

Finkenzeller, K. (2010). RFID Handbook Fundamentals And Applications In Contactless Smart Cards, Radio Frequency Identification And Near-Field Communication, Third Edition. United Kingdom: John Wiley \& Sons, Ltd.

Kamarulazizi, K., \& Ismail, W. (2010). Electronic Toll Collection System Using Passive RFID Technology. Journal of Theoretical and Applied Information Technology , 70-76.

Karygiannis, T., Eydt, B., Barber, G., Bunn, L., \& Phillips, T. (2007). Guidelines for Securing Radio Frequency Identification (RFID) Systems Recommendations of the National Institute of Standards and Technology. Gaithersburg, MD 20899-8930: National Institute of Standards and Technology.

Owunwanne, D., \& Goel, R. (2016). Radio Frequency Identification (RFID) Technology: Gaining A Competitive Value Through Cloud Computing . International Journal of Management \& Information Systems - Second Quarter, 20(2), 37-44.

Rachmat, H. H., \& Hutabarat, G. A. (2014). Pemanfaatan Sistem RFID sebagai Pembatas Akses Ruangan. ELKOMIKA: Jurnal Teknik Energi Elektrik, Teknik Telekomunikasi, \& Teknik Elektronika, 1(2), 27-39.

Santoso, \& Lesmana, D. (2014). Sistem Manajemen Aset Menggunakan Teknologi Radio Frequency Identification (RFID). Seminar Nasional Teknologi Informasi dan Komunikasi 2014 (SENTIKA 2014), (pp. 41-45).

Silaban, A. C. (2019). Kasus Tiket Palsu Coreng Wajah Baru Gelora Bung Karno. Diambil kembali dari https://kumparan.com/@kumparanbola/kasus-tiket-palsu-coreng-wajahbaru-gelora-bung-karno: https://kumparan.com.

Singh, N. K., \& Mahajan, P. (2014). Application Of RFID Technology In Libraries. International Journal of Library and Information Studies, 4(2), 1-9. 